\title{
SOBRE LA VERDAD EN EL PERIODISMO ${ }^{1}$
}

\author{
JULIo VÍCTOR Estremadoyro AlegGre \\ Universidad Nacional Mayor de San Marcos \\ \&
}

\section{Introducción}

Cuando un periodista informa sobre un desastre natural, con gran pérdida de vidas, las autoridades y las fuentes de primera mano dan cifras que son difundidas como verdades del suceso. Sin embargo, y la experiencia lo confirma, al día siguiente la cifras pueden haber cambiado $y$, por lo tanto, la verdad informativa es otra. Y así, sucesivamente, cada día habrá novedades y nuevas cifras verdaderas.

Aquí un ejemplo:

\section{TSUNAMIS EN EL SUDESTE ASTÁTICO}

\author{
Lunes 27 de diciembre 2004 \\ Tsumamis causaran más de 1,500 muertos en el Sudeste Asiático. \\ Martes 28 diciembre 2004 \\ La cifra de muertos en el sur de Asia superan los $25 \mathrm{mil}$ muertos. \\ Sábado 1 de enero 2005 \\ Ell número total de víctimas superó los $150 \mathrm{mil}$. \\ Miércoles 27 de Enero de 2005 \\ El número de muertos o desaparecidos después del maremoto que el 26 \\ de diciembre del 2004 arrasó el litoral del Coéano Indico supera los 280 \\ mil, luego de un nuevo recuento en Indonesia.
}

En el ejemplo se aprecia que día a día fue cambiando la verdad periodística, ya que los alcances del desastre eran otros en cada oportunidad, pero en realidad, profesionalmente hablando, lo que fue cambiando fueron las noticias del desastre. En otras palabras, en este contexto, noticia puede ser considerada como sinónimo de verdad periodística, en la tarea de informar. 
Del ejemplo se puede afimar que el periodista no busca la verdad absoluta y definitiva. El periodista busca la noticia, que no es lo mismo. El significado de la verdad periodística corresponde plenamente a lo sostenido por Aristóteles. Según el fil lósofo griego, una proposición es verdadera cuando lo que ella dice es como lo que dice. Así la proposición «la sangre es roja» es verdadera porque, efectivamente, la sangre es roja. En cambio, «Jauja es la capital de Junín», es falsa, porque Jauja no es la capital de Junín, es decir no es como dicha proposición dice que es.

Cuando se trata de saber qué es la verdad, se encuentran grandes dificultades. El concepto de «verdad» es el tema más importante de la filosofía. Desde la época de los griegos hasta nuestros días los más grandes filósofos han abordado el tema, sin llegar a un acuerdo universal.

\section{La verdad periodística}

Para los efectos de esta investigación acudimos a la llamada verdad objetiva que sostiene que el término verdad se usa primariamente en dos sentidos: el primero, para referirse a una proposición y, el segundo, para referirse a una realidad. En el primer caso se dice de una proposición que es verdadera diferenciándose de la falsa. En el segundo caso se dice de una realidad que es verdadera diferenciándose de la aparente, ilusoria, inreal, inexistente, etc.

No siempre es fácil distinguir entre dos sentidos de verdad porque una proposición verdadera se refiere a una realidad y de una realidad se dice que es verdadera. Pero puede destacarse un aspecto de la verdad sobre el otro. Es lo que ocurrió en la idea de verdad que predominó en los comienzos de la filosofía. Los filósofos griegos comenzaron por buscar la verdad frente a la falsedad, la ilusión, la apariencia, etc. Ia verdad era en este caso idéntica a la realidad, y ésta última era considerada como idéntica a la permanencia, a lo que es.

Los griegos no solamente se ocuparon de la verdad como realidad. Igualmente se ocuparon de la verdad como propiedad de ciertos enunciados, de los cuales se dice que son verdaderos. Aunque antes de Aristóteles ya se había concebido la verdad como propiedad de ciertos enunciados, la más celebrada fómula al respecto es la que se encuentra en Aristóteles: «Decir de lo que es que no es, o de lo que no 
es que es, es falso; decir de lo que es que es, y de lo que no es que no es, es verdaderos.

Aristóteles expresó por primera vez límpidamente lo que luego se llamará «concepción lógica», y que sería más adecuado llamar «concepción semántica» de la verdad. Por tanto, no hay verdad sin emunciado. En rigor, no hay enunciado como tal, pues un emunciado lo es siempre de algo. Para que un enunciado sea verdadero es menester que haya algo de lo cual se afirme que es verdad: sin la cosa no hay verdad, pero tampoco la hay sólo con la cosa. Esta relación del enunciado con la cosa enunciada ha sido llamada luego correspondencia o adecuación; la verdad es verdad del enunciado en cuanto corresponde con algo que se adecua al enunciado.

Y esto es lo que ocurre en el periodismo, en que el emunciado es la noticia y la realidad el hecho o la declaración a la que se refiere la noticia. Esto es lo que consideramos como la verdad periodística. Desde luego no es la verdad filasófica ya que el periodista no es un filósofo y los sucesos informativos no son absolutos e inmutables.

Como se afirmó al comienzo, en periodismo la realidad de los hechos puede ser distinta de un día para otro, lo que obliga a un nuevo enunciado o noticia. En otras palabras, la verdad periodística no es absoluta e inmtable, como pooría ser esta verdad: «el oro es amarillo», en el que el enunciado corresponde a una realidad inmodificable, así pasen los siglos.

Cuando un periodista informa sobre lo sostenido por un político en el sentido de que no está comprometido en ningún acto de corrupción, el reportero difunde una verdad periodística: «el político asegura que no está comprometido en ninguna inmoralidad». Si semanas después se descubre un video que revela que ese político estuvo involucrado en la cormupción, la veroad periodística será my distinta: «el político estuvo comprametido en la cornupción. Fue un cornupto.»

Esto es my fácil de entender en la práctica profesional del periodismo. Lo que es verdad en un momento dado, no lo puede ser, necesariamente, en otra circunstancia. El periodista informa sobre hechos o declaraciones. Su obligación es que su información sea objetiva, imparcial, honesta, responsable, pero, sobre todo, veraz. Es decir, informar con el mayor celo posible en la exactitud de sus datos. En 
otras palabras, informar sobre lo que se considera que es la verdad y sólo la verdad. Pero, como se ha indicado, la verdad en periodismo- es decir, la correspondencia entre el enunciado por la noticia y la realidadno depende solo del profesional: depende de los hechos y las declaraciones o testimonios que pueden, muchas veces, ser inexactos o disfrazar la exacta realidad. El periodista no puede penetrar en la mente de un declarante para concluir que miente, o que los hechos a los que no puede tener acceso directo o presencial, no son como las autoridades o supuestos testigos dicen que fueron.

Desde luego esto se presenta fundamentalmente en el periodismo diario, noticioso. El periodismo de investigación está dbligado a buscar la verdad más allá de la apariencia de los hechos o las declaraciones, porque es un periodismo que no trabaja con la urgencia del cierre de los diarios o de las ediciones apremiantes de la radio y la televisión.

Al respecto es bueno referirse a lo sucedido entre un congresista y el Canal 13 de Santiago de Chile. Ante la demanda civil intenpuesta por el senador Novoa contra dicho canal, por dar una información que afectaba su honra y que resultó falsa, la televisora contestó a la demanda afi imando que «no compete a los medios asegurar que lo que se transmite sea verdadero». Lo que ha reabierto el antiguo y nunca acabado debate acerca del grado de veracidad que corresponde exigir a los medios de commicación respecto de las informaciones que entregan. En este caso particular, entran en colisión dos derechos fundamentales: la libertad de informar y el derecho a la honra de las personas.

Todo esto nos lleva a concluir que la verdad periodística es, en algunos casos, circunstancial, temporal, variable. Y al respecto el periodismo responsable no debe estar atado a la información inicial sobre un hecho. Debe dar otra versión, otra verdad, en cuanto tenga elementos que varíen su primer informe.

En el anecdotario periodístico se puede recordar la actitud de un diario británico que se preciaba de no dar nunca noticias falsas. Un día informó que fulano de tal había muerto, lo que no era cierto porque el personaje vivía. No se rectificó ni se refirió más al personaje, hasta que un día publicó lo siguiente: « tal como lo informamos hace un tiempo, fulano de tal ha fallecidos. 
Dar siempre la verdad o esforzarse para lograrlo y rect ificarse cuando se descubre que la verdad dada no es tal, otorga a los periodistas y medios una de las más ambicionadas metas: la credibilidad. Tener credibil idad es poseer un capital inapreciable: la confianza del público.

\section{Aspectos de la verdad periodística}

En la dinámica de la comunicación periodística hay dos dimensiones que hay que tener en cuenta para entender la verdad en periodismo: la cobertura noticiosa y la información que el periodista da de esa cobertura.

En la cobertura, el reportero podrá tener los datos del suceso de manera directa, presencial, como en las conferencias de prensa, exposiciones, inauguraciones y actos diversos. Pero habrá coberturas en las que necesariamente requerirá acudir a diversas fuentes informativas. Sean testimoniales (declaraciones, denuncias, etc.) ,escritas o documentales, las fuentes ocasionarán que el periodista tenga una información indirecta y hasta subjetiva de los hechos.

En el aspecto de la información se puede precisar la que origina el periodista y la versión que difunde su medio. En el que origina el periodista cabe la tergiversación, la parcialización, la inexactitud o falsedad, debido a fuentes no confiables o no confirmadas. En la que da el medio, se puede producir la manipulación en sus diferentes manifestaciones.

Recuérdese el caso de la revista Quinto Poder que manipuló su información sobre el supuesto romance del Ministro de Comercio, Alfredo Ferrero y la ex Miss Perú Claudia Hemández. Desastre informativo basado en fuentes anónimas no verificadas y comprobadas. Un periodismo responsable de la verdad no se basa en expresiones: «en fuentes confiables se dijo»... «trascendió que»... «voceros bien informados».

Es en el asunto de la credibilidad de las fuentes informativas donde radica, de manera fundamental, la veracidad informativa, a tal extremo que en los últimos meses, debido a comprobadas fallas periooísticas, tanto en diarios como en la televisión, las grandes organizaciones editoriales del mundo han planteado y establecido radicales medidas 
que, inclusive, han motivado el despido de mumeroso profesionales, algunos notables figuras de la televisión informativa norteamericana.

Se pueden mencionar los siguientes ejemplos: ${ }^{2}$

\section{1) ㅌl caso de la $\mathrm{CBS}^{3}$}

Hace menos de un año, la cadena televisiva estadounidense CBS divulgó, en un documento de 224 páginas, los resultados de una minuciosa investigación de cuatro meses, con el propósito de determinar por qué se cometieron tantos errores éticos y profesionales en la difusión de un informe televisivo en el prestigioso programa noticioso «60 Minutos», dirigido por Dan Rather.

El segmento se trasmitió el 8 de septiembre del año pasado en plena campaña electoral y allí se atribuía a los familiares de George W. Bush el uso de influencias inapropiadas para que el actual presidente eludiera los rigores del servicio militar, en plena guerra con Vietnam. La acusación se sustentaba en documentos que más tarde resultaron falsos. El episodio estremeció los cimientos del periodismo investigativo estadounidense y puso en duda el rigor de un género periodístico -y de un programa en particular-que tiene, antes de salir al aire, pautas y reglas de conducta intema sumamente exigentes para verificar hasta el cansancio todas y cada una de las imágenes y palabras que se propalan y promuncian. La credibilidad es el principal capital de toda empresa periodística seria y cualquier amenaza contra ese principio debe ser severamente sancionada, para evitar erosionar la confianza depositada por la opinión pública en un medio de comunicación. En la televisión no se pueden decir mentiras ni medias verdades.

La CBS encargó a Dick Thomburgh (ex fiscal general) y Louis Boccardi (ex presidente de la Associated Press) llevar hasta sus últimas consecuencias esa pasión por la verdad y la objetividad que distingue al periodismo serio. Ambos escribieron una autopsia descarnada y precisa, desprovista de emociones y conjeturas, donde se hilvanan con rigor de cirujano los hechos y las circunstancias que precedieron a la elaboración del segmento noticioso.

El informe comienza describiendo el momento exacto en que arriba a la mesa de redacción la idea de elaborar una pieza sobre los recursos utilizados por Bush para escapar de la guerra de Vietnam. Y a partir de 
allí, se rastrea el lento y gradual proceso de transformación de una inexactitud en una mentira, así como el papel que desempeñaron los periodistas y prookuctores involucrados, hasta culminar finalmente determinando a algunos de los directivas de la cadena con el propósito de ocultar los errores cometidos y evitar que la verdad salga a flote.

El documento final debería ser el nuevo libro de consulta de cualquier profesional de la comunicación contemporánea. Allí se detallan, por ejemplo, los rigurosos procedimientos que acompañan a cualquier investigación, antes de que se propale; las distintas pruebas de verificación de los datos; la validez de las fuentes independientes; los pasos que se siguen para evitar contaminar la información con criterios subjetivos; la necesidad de separar la opinión de la información; la doligación de contrastar versiones y evitar prejuicios políticas o raciales o de cualquier otra índole a la hora de interpretar los datos y, sobre toob, tratar de vivir lo más lejos posible de las nefastas influencias del temido tótem del ráting: el sometimiento, en suma, a los rigores implacables de la verdad. Como decía Sherlock Holmes: «Déme solo los hechos, señora, los hechos».

Ia actitud de los directivos de CBS ha sido quirúrgica, si cabe el término. Ha despedido a tres altos ejecutivos, lo mismo que a los productores del informe. También ha aceptado la renuncia de Dan Rather, sin lugar a dudas, el periodista más serio de la cadena.

Y lo que ha sido realmente un paso adelante en esa maniática obsesión por conquistar la verdad para ofrecerla tal vez como nuevo anillo de compromiso nupcial a la opinión pública: se ha creado una nueva división ejecutiva, nombrando a un alto responsable de la cadena para que se encargue exclusivamente de verificar que todos y cada uno de los pasas previstos en una investigación se cumplan religiosamente. Antes de difundir un informe cualquiera, el periodista tiene que demastrarle a su cadena que dice la verdad. Es la primera prueba de fuego.

Hay que conseguir que el televidente encienda su pantalla y sintonice un programa noticioso, sabiendo a ciencia cierta que toob lo que allí se dice es verdad, confiando en que no se le va a engañar. El día que conquistemos ese estatus -parecen decirnos los autores de esta investigación- tal vez podamos miramos de frente, cara a cara, sabiendo finalmente quiénes somos. Y no ser lo que otros imaginan. 


\section{2) El caso The New York Times ${ }^{4}$}

The New York Times, uno de los mejores periódicos del mundo, dictó hace unas semanas un decálogo con la finalidad de recuperar su recientemente dañada credibilidad. Esos «Diez Mandamientos» van dirigidas a los periodistas de la redacción y pretenden evitar fraudes y los plagios como los llevados a cabo por su ex redactor Jayson Blair, escándalo que provocó la dimisión del director y del director adjunto del rotativo.

Un comité interno formado por once redactores jefes, seis reporteros, un corrector y un fotógrafo han sido los encargados de elaborar un informe con la intención de aumentar la confianza de los lectores en el diario. «Son muchas las cosas que podemos intentar para mejorar la calidad del periodismo que hacemos», declaró su actual director, Bill Keller, tras el escándalo protagonizado por el ex reportero.

Entre las diversas medidas que se recomiendan en este decálogo, que responde a la iniciativa lanzada el pasado otoño por su actual director, Bill Keller, está la de limitar al máximo la atribución de informaciones o declaraciones a fuentes no identificadas, el diferenciar claramente entre información y opinión y reducir el número de errores (en 2004 fueron detectados 3200) .

El comité también les aconseja acercarse lo más posible a los lectores mediante la página digital. No sólo para ofrecerles los documentos íntegros usados en sus artículos y reportajes, sino que se recomienda al director y a los subdirectores que se alternen para escribir una columna quincenal en la que aborden asuntos sobre el periódico.

Se recomienda a la redacción una mayor agresividad con las fuentes para que se reconozca la atribución de las citas; y a los editores, que presionen en este aspecto a los redactores. Finalmente se aconseja que el diario mejore su interacción con la radio y la televisión y reclute, entrene y pague a redactores voluntarios para que estos desarrollen sus contactos con grupos sociales, iglesias, campus universitarios y lo que se considere oportuno.

A la pregunta de si la implantación de las recomendaciones logrará acabar con la actual desconfianza del público sobre los medios de commicación, el director del «limes» responde: «Por supuesto que no». 
El actual director considera que hay demasiados factores que escapan al control del más prestigioso diario de Estados Unidos. Aquí los «Diez Mandamientos» :

1 Que el editor ejecutivo y los dos editores jefe compartan la responsabilidad de escribir regularmente una columna que trate de los asuntos que afecten al periódico.

2. Hacer a los reporteros y editores más accesibles a través del correo electrónico.

3. Usar la página web para que los lectores puedan acceder a los documentos íntegros usados para las historias así como las transcripciones de las entrevistas.

4. Considerar la opción de crear un blog que promueva la interacción con los lectores.

5. Reducir el uso de fuentes anónimas.

6. Que los reporteros confirmen la veracidad de sus artículos con sus fuentes antes de su publicación y que soliciten declaraciones suyas después de que la información haya salido a la luz.

7. Establecer un sistema de rastreo de errores. En el último año fueron detectados hasta 3200.

8. Desarrollar un software para detectar casos de plagio.

9. Incrementar la cobertura de las áreas rurales de América y ofrecer más noticias sobre religión.

10. Establecer un sistema para evaluar los ataques contra el trabajo de The New York y determinar si deben se respondidos y cómo hacerlo.

\section{3) ㅌl caso de la BBC}

La BBC quiere obligar a sus periodistas a revelar la identidad de una fuente en los casos de informaciones delicadas que se basen en una sola fuente. Para ello creará una escuela de periodismo con el dojetivo de cerciorarse de que toda la plantilla de periodistas tiene la formación adecuada. Ésas son las dos propuestas más llamativas presentadas por Ron Neil, un antiguo director de informativos de la corporación, para corregir los problemas puestos de manifiesto por el llamado caso Kelly.

Fl suicidio de David Kelly, un científico experto en Irak y en armas de destrucción masiva, convirtió en crisis política la batalla de 
acusaciones mutuas que enfrentó la primavera y el verano pasado a la BBC y al Gobierno laborista. La escaramuza, provocada por unas informaciones del periodista Andrew Gilligan en las que acusaba al Gobierno de haber exagerado de manera deliberada los peligros que suponía Sadam Husein, terminó con un humillante dictamen del juez lord Hutton a favor del Gobiemo y en contra de la BBC. Tras la dimisión del presidente y del director general del ente, la conporación se sumió en un proceso de autocrítica del que han salido estas recomendaciones, respaldadas por el nuevo director general, Mark Thompson.

La corporación invertirá varios millones de dólares en mejorar tanto la formación de sus actuales periodistas como de los del futuro. El tomar notas de manera «precisa y fiable» será uno de los objetivos prioritarios y los ascensos en la redacción tendrán en cuenta no sólo la experiencia sino la formación de los periodistas.

El sindicato de periodistas dio la bienvenida al amuncio de creación de la escuela, pero alertó sobre los peligros que encierra la propuesta de forzar a los periodistas a revelar la identidad de sus fuentes. Paul McLaughlin, representante del sindicato que negocia con la BBC la puesta en marcha de las recomendaciones del informe Neil, recordó ayer que los jueces británicos no tienen derecho a exigir a un periodista que revele la identidad de sus fuentes.

«Tenemos que dejar absolutamente claro a la gente que informa a la BBC que sus nombres no serán revelados a la dirección sin su consentimiento previo», declaró. El jefe de informativos aclaró que ese extremo no será utilizado de manera automática y que, en cualquier caso, los superiores podrán negarse a difundir la noticia en cuestión o renunciar a esa exigencia si lo consideran adecuado.

\section{Características de la verdad periodística}

Si quisiéramos clasificar a la verdad periodística, según la realidad de los sucesos, podríamos hacerlo según este cuadro:

Progresiva: Es el caso con el que iniciamos este estudio. Típica de las coberturas de tragedias y catástrofes de gran magnitud, en las que las cifras de las víctimas y alcances de los daños aumentan a medida que pasan los días. 
Modificable: En sucesos conflictivos, como el amuncio de la liberación de un peligroso delincuente que dará lugar a una reacción enérgica que puede anular esa liberación. Igualmente en investigaciones en curso, en las que testigos y testimonios pueden cambiar.

Definitiva: Se aplica a hechos concretos y únicos que ocurren en el día, sin ninguna posibilidad de cambio.

Manipulada: Cuando se dan versiones parcializadas de un solo lado o posición. Se da preferencia a declaraciones de un punto de vista o de un partido político, por ejemplo. También cuando se omiten o minimizan determinadas informaciones,

Inventada: Cuando se afirma algo que sólo está en la mente del periodista. Tal los casos en que se informa de declaraciones o hechos que nunca se han producido, pero que podrían tener algún grado de verisimilitud. Ocurre mucho en la política, policiales, espectáculas y deportes.

Controversial: Cuando se debe dar las versiones de partes en conflicto. Cada una tiene su verdad. Para una información imparcial hay que dar oportunidad a que todas se manifiesten.

Seguible: Ocurre cuando se hacen denuncias o revelaciones que van a requerir confimaciones, ampliaciones y muevos ángulos noticiosos.

Provocada: Cuando se fuerzan hechos para obligar a una cobertura noticiosa. Esta situación se produce, por ejemplo, en las demostraciones huelguísticas, con interrupción de carreteras y otras medidas. Es conocido que manifestantes desganados, de repente cobran un vigor inusitado y espectacular en cuanto ven cámaras de televisión. Alejadas éstas, vuelven a su modorra. Pero el caso más concluyente fue el que protagonizaron Abimael Guzmán y su grupo senderista en la frustrada audiencia de su juzgamiento en la Base Naval del Callao. Aprovecharon la presencia periooística, en especial de la televisión, para protagonizar uno de los espectáculos más bochornosos de los últimos tiempos, con lo cual lograron sus propósitos: que el periodismo al cumplir con su dbligación de informar la verdad periodística de lo sucedido, difundiera proclamas y expresiones pro terroristas. 
Jurio Víctor Estremadoyro AimgGre

\section{Notas}

1 Capítulo de la investigación del autor sobre El saber científico del periodismo.

2 Los ejemplos incluidos a continuación han sido, en algunos casos, reescritos a partir de las fuentes citadas para cada caso.

3 PEREIRA, Rodolfo: «La CBS y una enseñanza para el periodismo». El Comercio. 18/01/2005

4 SÁNCHEZ BUJANDA, Javier: «Los Diez Mandamientos de The New York Times». www.periodistadigital.com 11/05/2005

5 «La BBC exige a sus periodistas revelar las fuentes en casos delicados». www.periodistadigital. com 25/06/2004. 